
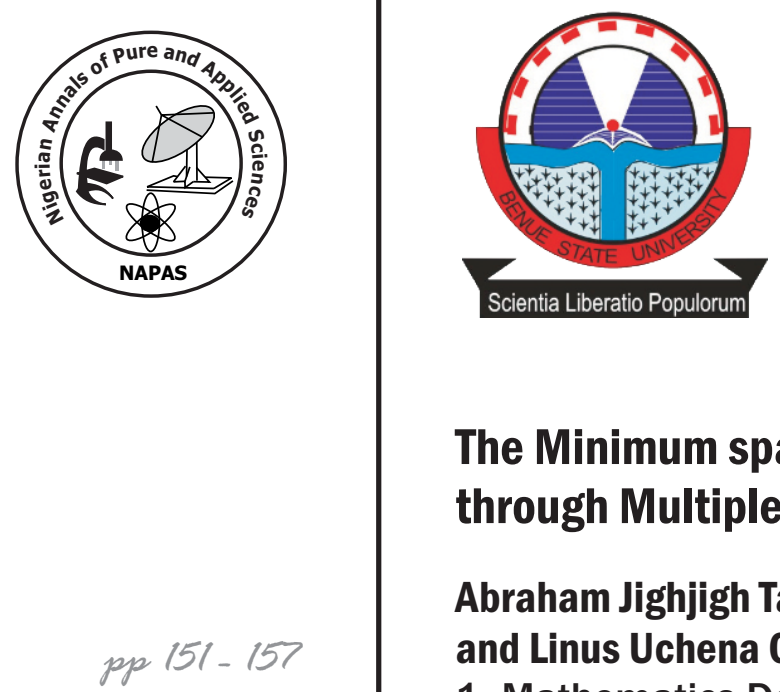

\title{
The Minimum spanning Tree of the Nigeria roads Network through Multiple-Roads Network System
}

\author{
Abraham Jighjigh Tamber ${ }^{1}$, Festus. 0. Ikpotokin ${ }^{2}$ \\ and Linus Uchena Okafor ${ }^{3}$ \\ 1. Mathematics Department, \\ Benue State University Makurdi, Benue State, Nigeria \\ atamber@bsum.edu.ng \\ 2. Computer Science Department, \\ Ambrose Alli University, Ekpoma, Edo State, Nigeria. \\ festusikpotokin@aauekpoma.edu.ng \\ 3. Mathematics Departtment, \\ Nigerian Defense Academy Kaduna, Kaduna State Nigeria
}

\begin{abstract}
The research work is aimed at finding the optimal graph of the Travel Salesman Problem of the vehicular movement from multiple sources of the Nigeria roads network of the coastal towns: Lagos, Port Harcourt, Asaba and Calabar through the hinterland to multiple destinations (border towns) of Katsina, Sokoto and Maiduguri so as to minimize the cost of fueling, maintenance and loss customers and goods/services get delivered to destinations in good time. In obtaining the optimal graph, the Kruskal algorithm of the minimum spinning tree was used and was implemented by a computer application package, TORA, developed by Taha. The optimal minimum spinning graph is: Lagos - Abeokuta - Ibadan - Osogbo - Ilorin - Osogbo - Akure Ado Ekiti - Akure - Benni - Asaba - Owerri - Port Harcourt - Umuahia - Uyo - Calabar - Uyo - Umuahia Port Harcourt - Owerri - Asaba - Benni - Awka - Enugu - Abakelike - Enugu - Awka - Benni - Akure Lokoja - Abuja - Minna-Abuja - Kaduna - Kano - Katsina - Kano - Dutse - Kano - Gasua - Sokoto - Brini Kebbi - Sokoto - Gusau - Kano - Kaduna - Abuja - Lafia-Makurdi - Lafia - Jos - Bauchi - Gombe - Yola Jalingo-Yola-Gombe-Damaturu-Maiduguri with the total distance of $8327 \mathrm{Km}$.
\end{abstract}

Key words: Travel Salesman problem, minimum spinning tree, roads network, multiple sources, multiple destinations, 


\section{Introduction}

Network of roads have become very important for road transporters, since it serves as a channel of moving people, goods and services from one place to another. Anyanwu, et al. (1997) noted that, transportation is important to every nation. All towns produce or need products. These products must get there somehow. Cargo movement by trucks, trains, planes and boats is the most essential part of a business. Therefore, for businesses to be able to sell their products locally, nationally or worldwide, to make a profit and grow larger, they must also be able to receive shipment of raw products which they need to make their items. The other side of transportation is moving people. People need to go places and getting there on horses back is not the best option. Plane, trains, buses, boats, cars etc, all need to be made, maintained and some are staffed. Hence transportation creates jobs. He further noted that, of all commodity movements to and fro the sea-ports and airport, at least, two-thirds are handled by road transport while up to $90 \%$ of all other internal movements of goods and persons take place by roads. He also noted that, Nigeria roads network is linked together all over the 36 states and the Federal Capital Territory with arterial roads which are interconnected with sub-arterial, distributor or collector roads and local roads. These constitute a road network data.

It has been stated that, transportation system in Nigeria started as far back as precolonial era. The first form of transport was shanks pony (i.e. human foot), within this period, transportation facilities such as roads, railways, and air transport facilities were really non-existent with emphasis then on the bush path.

However, Tim (2013) noted that, people eventually learnt to use animals such as donkeys, horses, camels, etc., i.e. animals were domesticated for transportation. As the years went by, different modes of transportation were invented and improved. With improvement, there are many modes of transportation. Each mode has a fundamentally different technology, and requires a separate environment and also has its own infrastructure, vehicles and operations which often have unique regulations.

Tim added that, the main modes of transport in Nigeria: Air, Land (Rail and Road),
Water and Other modes (Pipeline and pneumatic, tubes, Electronic, Cable, Space and Animals transport).

Even though, all these modes of transportation play a significant role in the economic growth and development of Nigeria both directly and indirectly. This paper seeks to obtain the possible minimum spanning tree (MST) for vehicular movement from multiple sources to single destination through multipleroads network system so as to minimize the cost of fueling, maintenance and loss customers and get to their destinations deliver in good time.

The minimum spanning tree or MST problem is one of the simplest and best-studied optimization problems in computer science and many other areas. The MST problem is to obtain a spanning tree of minimum total weight. Remarkably, this optimization version of the problem can be solved in little worse than $\mathrm{O}(\mathrm{m})$ time. The problem has obvious applications to network organization and touring problems. It also arises frequently in other guises. For example, the single-link clustering technique, used by statisticians to partition data points into coherent groups, or to choose a tree topology for dendroid distributions, is essentially MST under another name (Eisner, 1997).

Network optimization has always been at the heart of operations research. Shortest route model is one of the network models which applications cover a wide range of areas such as telecommunications, agriculture, petroleum, education, military, road constructions, e.t.c., (Sohana and Sazib, 2011).A minimum spanning tree (MST) of a weighted graph $\mathrm{G}$ is a spanning tree of $\mathrm{G}$ whose edges sum to minimum weight. In other words, a minimum spanning tree is a tree formed from a subset of the edges in a given undirected graph, with two properties:

(1) It spans the graph, i.e., it includes every vertex in the graph, and

(2) It gives the minimum, i.e., the total weight of all the edges is as low as possible.

The minimum spanning tree problem is always included in algorithm textbooks since:

(1) It arises in many applications,

(2) It is an important example where greedy algorithms always deliver an optimal solution, and

(3) Clever data structures are necessary to 
make it works efficiently.

MST is fundamental problem with diverse applications such as: Dithering, Cluster analysis, Max bottleneck paths, Real-time face verification, LDPC codes for error correction, Image registration with Renyi entropy, Find road networks in satellite and aerial imagery, Reducing data storage in sequencing amino acids in a protein, Model locality of particle interactions in turbulent fluid flows, Autoconfigures protocol for Ethernet bridging to avoid cycles in a network, Approximation algorithms for NP-hard problems (e.g., TSP, Steiner tree),Network design (communication, electrical, hydraulic, computer, road) etc.

Bang and Chao (2004) explain Boruvka's Algorithm, Prim's Algorithm and Kruskal's Algorithm as the most popular MST algorithms, he added, Minimum spanning trees are useful in constructing networks, by describing the way to connect a set of sites using the smallest total amount of wire. Much of the work on minimum spanning trees has been conducted by the communications company such as Cable TV, Circuit design, Islands connection, Clustering gene expression data etc.

Zongxiang (2013) noted that, multiple sources-multiple destination network deals with many origins and stops with attempts to achieve the shortest total distance. He remarked that, it plays an important role in saving gas, time and money and has application in a wide range of industries such as transportation, travel planning and delivery services. Haven taken a close look at the previous works and their lapses, this study will seek to model and obtain the MST for vehicular movement of Nigeria roads transportation network system from multiple sources (Lagos, Asaba, Warri, Port Harcourt and Calabar) to single destination (Katsina) so as to minimize the cost of fueling, maintenance, reduce risk and get to their destinations in good time.

\section{Methodology and Data Collection Model Formulation}

This network analysis of MST focuses on the vehicular movement of Nigeria roads transportation network system from multiple sources (Lagos, Asaba/Warri, Port Harcourt and Calabar) to single destination (Katsina) so as to minimize the cost of fueling, maintenance, reduce risk and get to their destinations in good time. The major constituents are the major city distance chart of Nigeria and Nigeria roads network system as shown in Fig 1 and Fig 2 below respectively.

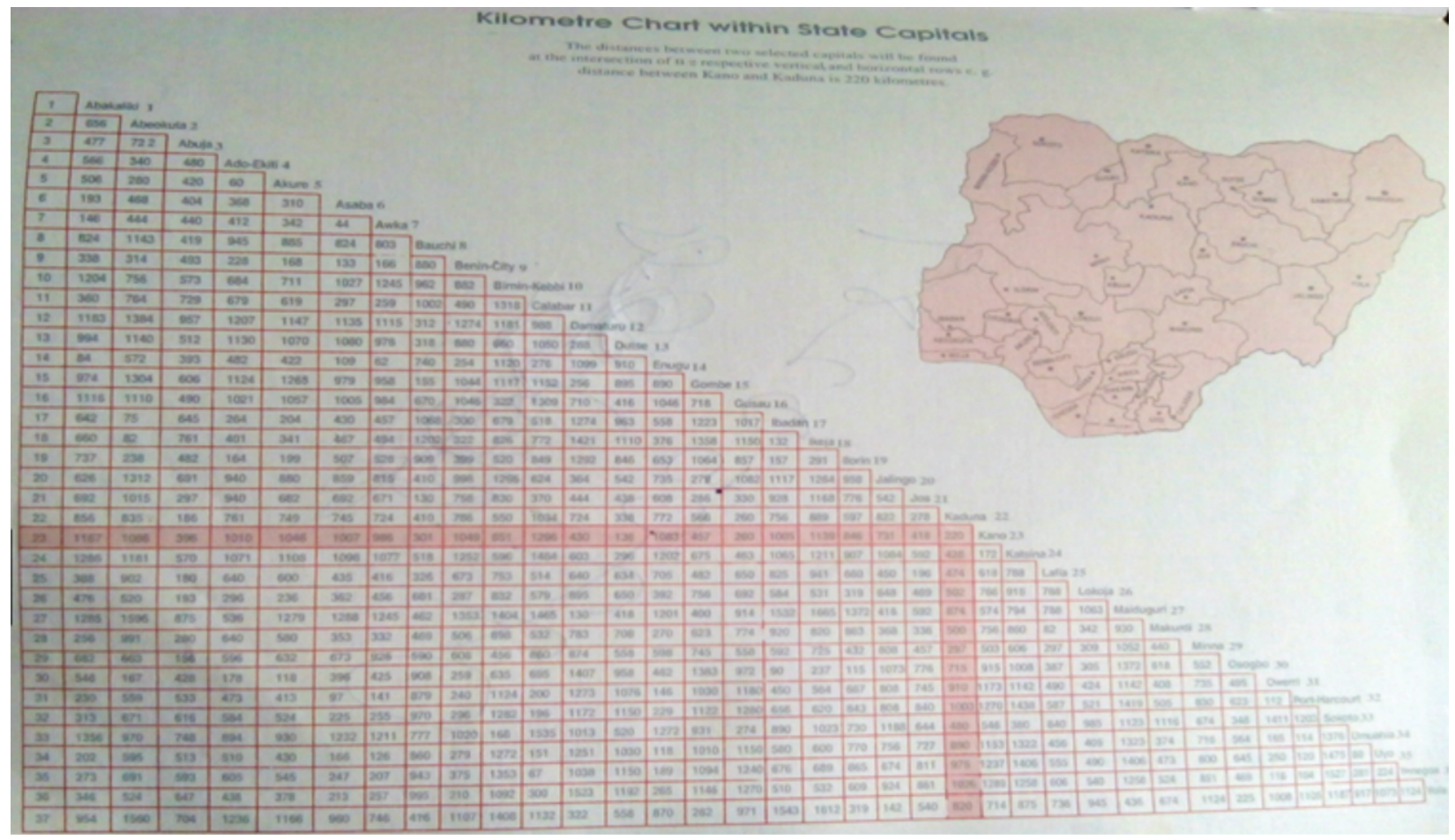




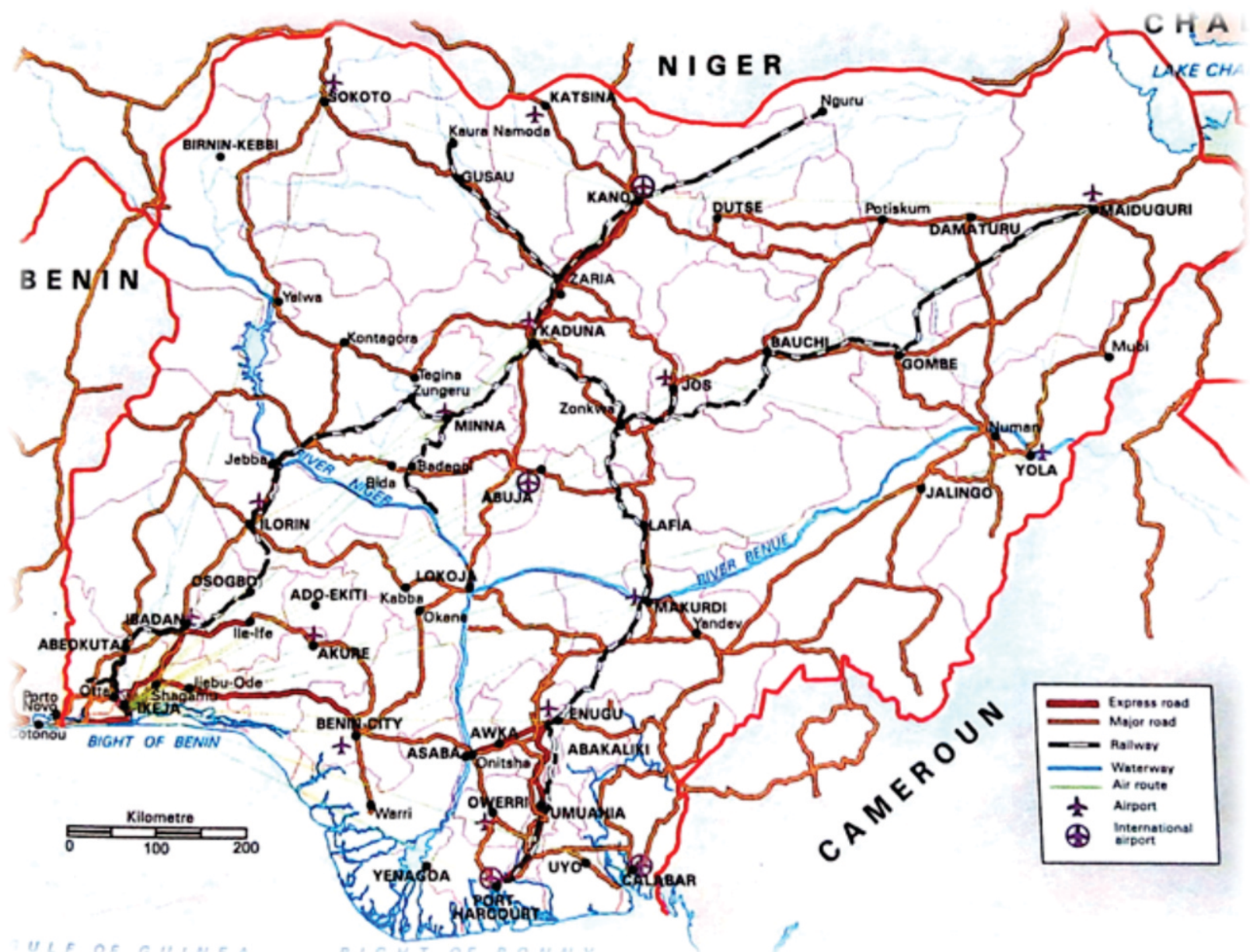

Fig 2 Nigeria Roads Network System

\section{Model}

The network was modeled out of Fig 2 and Fig 1 above as shown in Fig 3 below.

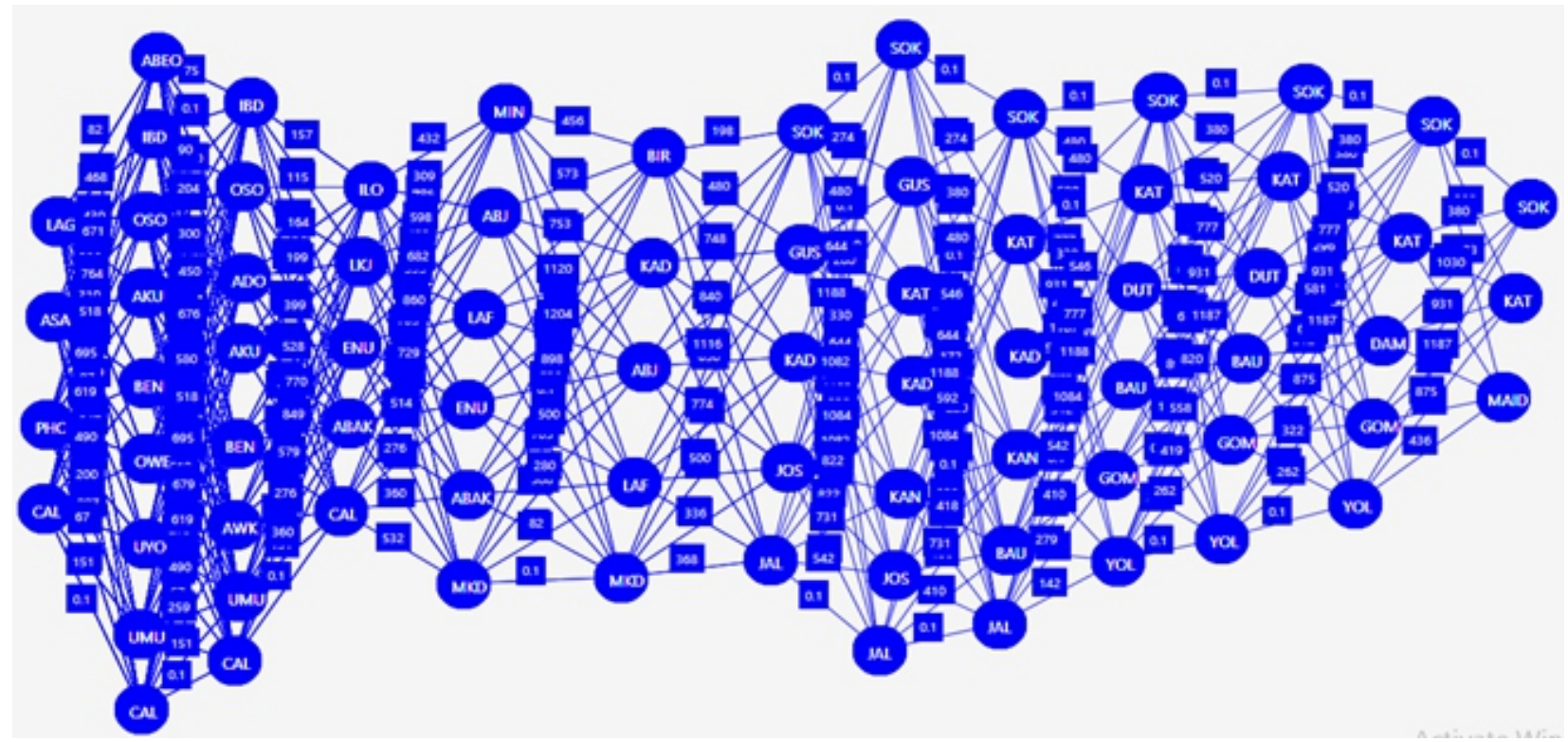

Figure 3: Nigeria road network of motorable road from multiple sources (coastal towns: Lagos, Port-Harcourt, Asaba/warri and Calabar) to multiple destinations (border towns: Katsina, Sokoto and Maiduguri) 


\section{Analysis}

These data were subjected to the Kruskal's Algorithm which was given by Joseph Kruskal in 1956 using a computer package TORA developed by Taha (2007). It creates a forest where each vertex in the graph is initially a separate tree. It then sorts all the edges in the graph. For each edge $(u, v)$ in sorted order, we do the following. For vertices $u$ and $v$, belong to two different trees, then add (u, v) to the forest, combining two trees into a single tree. It proceeds until all the edges have been processed.

\section{Algorithm: Kruskal}

Input: A weighted, undirected graph $\mathrm{G}=(\mathrm{V}$, E, w ).

Output: A minimum spanning tree $\mathrm{T}$. Sort the edges in $\mathrm{E}$ in no decreasing order by weight.

$\mathrm{T} \leftarrow \varnothing$
Create one set for each vertex.

for each edge $(u ; v)$ in sorted order do

$$
\begin{aligned}
& \mathrm{x} \leftarrow \operatorname{Find}(\mathrm{u}) \\
& \mathrm{y} \leftarrow \operatorname{Find}(\mathrm{v}) \\
& \text { if } \mathrm{x} \neq \mathrm{y} \text { then } \\
& \mathrm{T} \leftarrow \mathrm{T} \mathrm{U}\{(\mathrm{u}, \mathrm{v})\} \\
& \text { Union }(\mathrm{x}, \mathrm{y})
\end{aligned}
$$

\section{Main Idea}

- $\quad$ Start with $|\mathrm{V}|$ disjoint components

- $\quad$ Consider lesser weight edges first to incrementally connect components.

- $\quad$ Make certain to avoid cycles.

- Continue until spanning tree is created.

\section{Results/Discussion}

Subjecting data in Fig 3 to the Kruskal's Algorithm using a computer package TORA developed by Taha (2007), the following result was obtained see Fig 4:

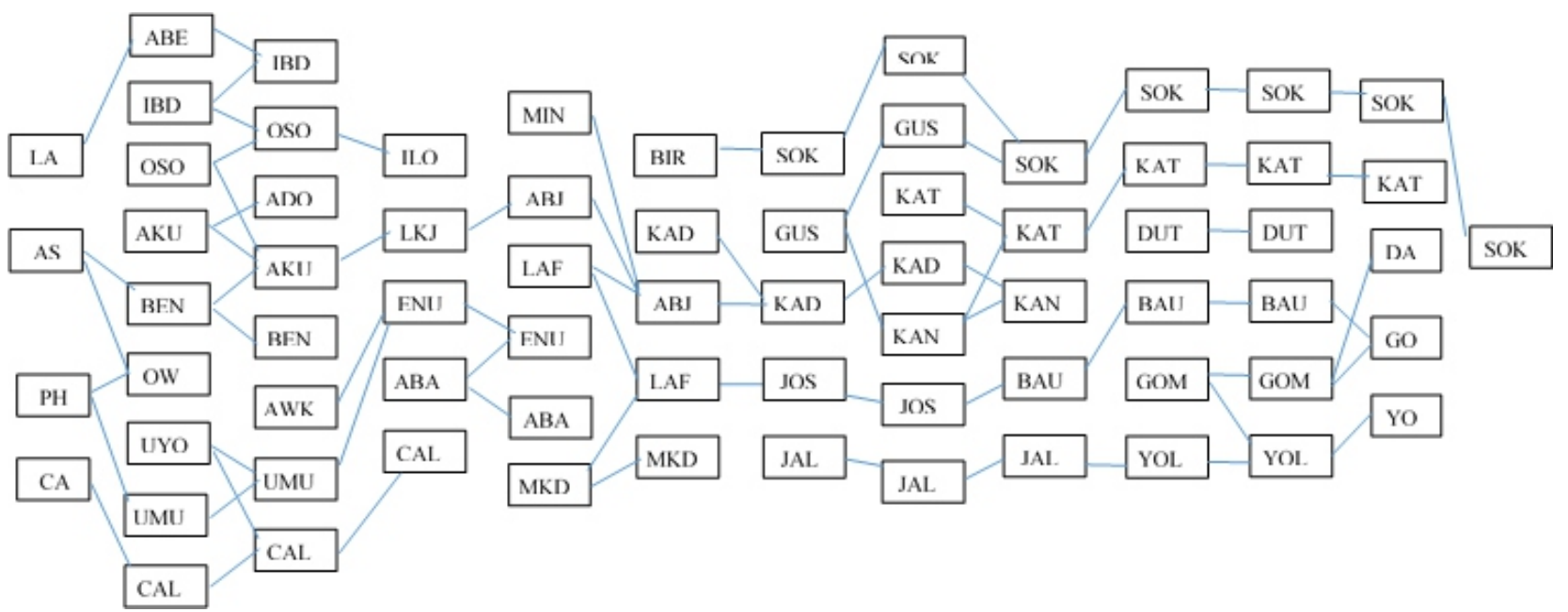

Fig 4: Minimum Spanning Tree Nigerian Roads Network from Coastal Cities through hinterland to extreme town (Lagos, Warri/Asaba, Port Harcourt Calabar to Katsina).

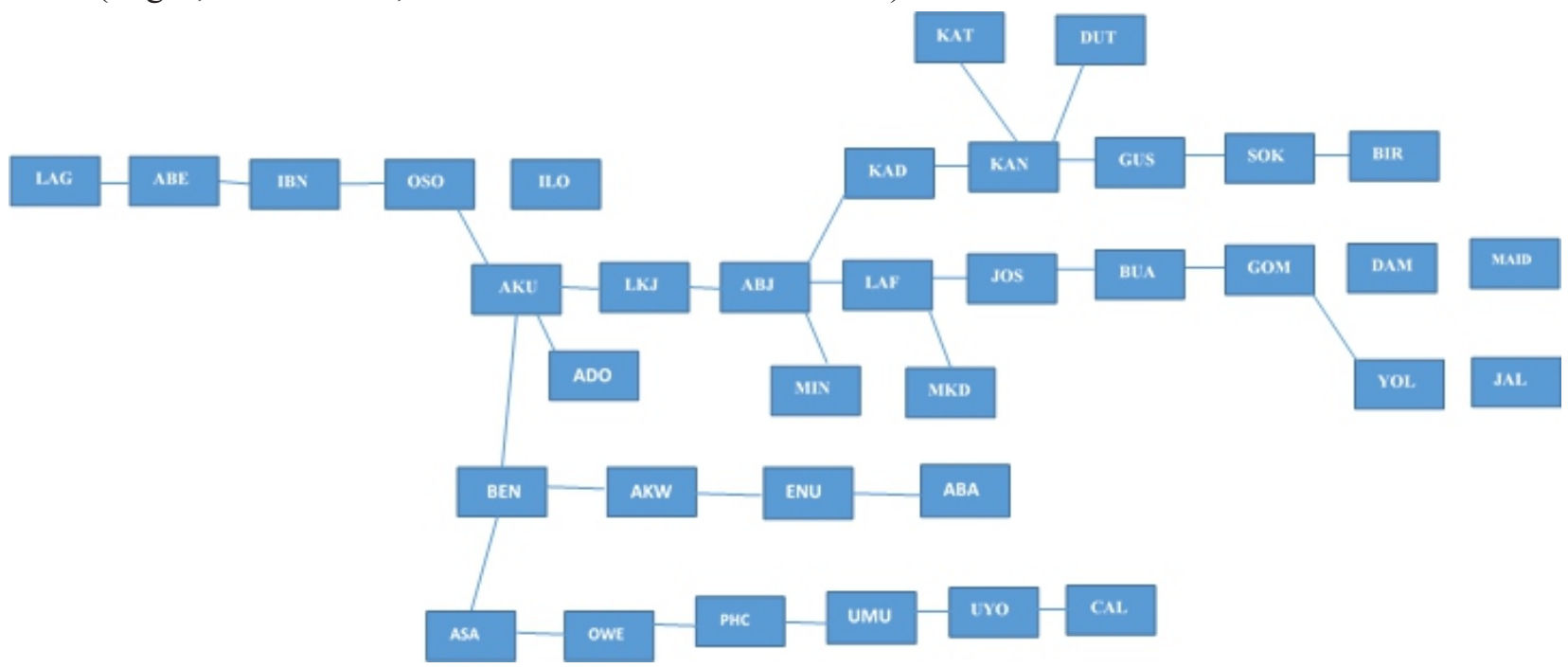

Fig 5: Summary of Minimum Spanning Tree of Nigerian Roads Network from Coastal Cities through hinterland to extreme town (Lagos, Warri/Asaba, Port Harcourt Calabar to Katsina). 
From Fig 5, minimum spinning tree of Nigerian Roads Network from Coastal Cities (Lagos, Warri/Asaba, Port Harcourt Calabar through hinterland to extreme town (Katsina, Sokoto and Maiduguri) with the distances between the cities are as follow: Lagos -82Abeokuta -75- Ibadan -90- Osogbo -115Ilorin -115-Osogbo -118-Akure -60-Ado Ekiti -60- Akure -168- Benin -133- Asaba -97Owerri -112- Port Harcourt -114-Umuahia -88Uyo -67-Calabar-67-Uyo-88-Umuahia -114Port Harcourt -112- Owerri -97- Asaba -133Benin -166-Awka -62-Enugu -84-Abakelike 84-Enugu -62-Awka -166-Benin -168-Akure -238- Lokoja -193- Abuja -155- Minna 155-Abuja -105- Kaduna -220 - Kano -172Katsina -172- Kano -136- Dutse -136- Kano 260- Gasua -274- Sokoto -168- Birni Kebbi 168- Sokoto -274- Gusau -260- Kano -105Kaduna -220- Abuja -180-Lafia -82-Makurdi -82- Lafia -196- Jos -130- Bauchi -155Gombe -262- Yola -142- Jalingo -142- Yola 262- Gombe -256- Damaturu -130- Maiduguri with the total distance of $8327 \mathrm{Km}$.

\section{Conclusion}

In order for a transport or service provider (in Nigeria) to minimize the cost of fueling, maintenance, reduce risk and get to their destinations in good time, this model should be adopted, i.e. Lagos - Abeokuta - Ibadan Osogbo - Ilorin - Osogbo - Akure - Ado Ekiti Akure - Benni-Asaba-Owerri - Port Harcourt - Umuahia - Uyo - Calabar - Uyo - Umuahia Port Harcourt - Owerri - Asaba - Benni - Awka - Enugu - Abakelike - Enugu - Awka - Benni Akure - Lokoja - Abuja - Minna -Abuja Kaduna - Kano - Katsina - Kano - Dutse Kano - Gasua - Sokoto - Brini Kebbi - Sokoto Gusau - Kano - Kaduna - Abuja - Lafia Makurdi - Lafia - Jos - Bauchi - Gombe - Yola - Jalingo - Yola - Gombe - Damaturu Maiduguri with the total distance $8327 \mathrm{Km}$.

\section{References:}

Ahuja R.K., Magnati T. L., Orlin J. B., and Reddy M. R. (1995). Applications of Network Optimization. Handbook in OR and MS, Vol. 7 Elsevier Science B.V.

Anyanwu, J. C., Oaikhena, H., Oyefusi, A. and Dimowo, F. A. (1997). The Structure of the Nigerian Economy (1960-1977)
Onitsha, Nigeria: Joanne Educational Publishers Ltd.

Ehsan M. and Hunter A. (2012), Multi-criteria Path Finding International Archives of the Photogrammetry. Remote Sensing and Spatial Information Sciences, Volume xxxix-B2, 2012 xxiii ISPRS congress, 25 August -01 September 2012, Mel-bourne Australia.

Gubichev A., Bedathur S., Seufert S. and Weikum G. (2010).Fast and Accurate Estimation of Shortest Paths in Large Graphs. CIKM'10 October 26-28, 2010, Toronto, Ontario Canada. h t t p : / / w w w . bi o i m f. u n i ;leipzig.de/nalexander/HIBIO9.pdf

https://en.wikipedia.org/w/index.php?tittle=flo

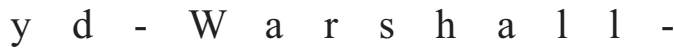
algorithm\&oldid $=700575112$

https://en.wikipedia.org/wiki/dynamicprogramming algorithm/

Rabbat M. Nowak R. Coates M. (2004) Multiple Sources, Multiple Destination Network Topology IEEE INFOCOM 2004, 077803-8356-7/04/\&20.00

Rashid and Tariq R.S. (2015), Path Analysis Using Arc GIS Web API: UAE Data PERSPECTIVES. Journal of Geosciences and Geometrics, Vol. 3, No.s 1 http://pubs.sciepub.com/igg/3/1/4

Schrijver A. (2012). On the History of the Transportation and Maximum Flow Problems. Documenta Mathematical/ . Extra Volume ISMP(2012).

Sharma J. K. (2011) Operations Research Theory and Applications, Fourth Edition, by Macmillan Publishers India Ltd.

Sohana J. and Sazib H. M (2011). A Comparative Study on Algorithm for Shortest Problem and some Extensions. International Journal of Basic and Applied Science; vol. 11 issue 6.

Tamber A. J. (2015). Optimal Transportation Network Using Certain Challenges As Catalytic Factors On Nigerian Routes And Traffic Forecast. A Thesis in the Department of Mathematics, Faculty of Science, Submitted to the Postgraduate School, Nigerian Defense Academy Kaduna.

Tim, L. (2013). A Brief History of Transportation.www.localhistories.org 
Ullrich A. and Forst C.V. (undated), K- Path A: K- Shortest Path Algorithm Wang Q., Zhang Z., Zhang Y. and Deng Y. (2012). Fussy Shortest Path Problem Based on Biological Method. Journal of Information and Computational Science 9:5 1365-1371. http://www.joic.com

Zongxiang Y. (2013). A Divide and Conquer Algorithm for Multiple Stop Routing Microsoft Corporation 2013
Washington GIS Conference

Eisner J. (1997) State-of-the-Art Algorithms or Minimum Spanning Trees A Tutorial Discussion, University of Pennsylvania

Bang Y. W. and Chao K. (2004). An excerpt from the book "Spanning Trees and Optimization Problems, Chapman \& Hall/CRC Press, USA.

Taha A. H. (2007) TORA Optimization system, Winder® Version 2.0 